Mote: «A liberdade hoje, manas, é a persistência do riso de quem aguentá-lo pode sem esgar»

\title{
A liberdade é a persistência do riso que é a persistência da liberdade
}

\section{Catherine Dumas e Agnès Levécot}

CREPAL - Université de la Sorbonne Nouvelle-Paris 3

0 riso multifacetado das Novas Cartas Portuguesas é um parâmetro persistente ao longo da obra. Com efeito, segundo conta Maria Teresa Horta a propósito da génese do livro, este foi escrito ludicamente, com a ajuda de um grande riso, mas riso consciente do perigo que corriam as autoras ao publicá-lo. Estudaremos as diferentes facetas que fazem do motivo riso uma das características inovadoras do livro. Mas queremos afirmar de entrada que o 
riso se integra numa linha de força: a proposta dum novo sujeito.

Johan Gottlieb Fichte, no encalce de Kant, inaugura o idealismo alemão e concebe um conjunto conceptual fundamental para o Romantismo alemão, e que inspirou também as filosofias do sujeito da nossa contemporaneidade. Julgamos ser este aparelho conceptual de primeira ordem para esta glosa do mote de Novas Cartas Portuguesas que nos foi atribuído. Quando Fitche disserta sobre a liberdade, fala de uma "consciência absoluta" e de um "sujeito absoluto". Para chegar à condição de "absoluto", o sujeito tem que, através de um acto libertador, conjugar simultaneamente a sua "auto-consciência" pré-reflexiva e a sua consciência. Propomos aqui considerar o riso como aquele acto libertador que constitui o "sujeito absoluto", e que seria o da sororidade. Um tal sujeito colectivo visa constituir-se em Novas Cartas Portuguesas como implicação política, determinante para a história do seu tempo e do futuro.

A força de imposição de tal sujeito inscreve-se plenamente na noção de "ser verdadeiro" de Fichte, esse "quem aguentá-lo pode" do mote. Queremos a seguir pormenorizar a nossa análise do mote através das repetidas ocorrências do riso como processo e das suas projecções literárias.

Começaremos pela qualidade do riso enquanto "acto libertador", ou seja o riso "sem esgar". Novas Cartas Portuguesas opera a libertação de um riso que Mariana associa à vingança: “(assim vos recuso, de vós me liberto um pouco - ó vingança, ó riso...)” (Barreno/Horta/Costa 2010: 51). Trata-se do riso parado, detido na prisão do convento de Beja pela recusa obrigada ao mundo (idem: 54). 0 peso do "esgar" mortífero ("Assim me envolvo no medo do peso do corpo que me arrasta e me desguarnece do riso, ancorada a mim"; idem: 306) opõe-se à leveza do "riso suavinho" (idem: 283). Poïesis em si, o riso libertador actua tanto no lema da "poesia liberdade livre" rimbaldiana, postulado político adoptado, mais perto de nós, por um Ramos Rosa, como no frenesim da louca ou da bruxa. Escreve Ariane Bayle no seu prefácio ao livro colectivo intitulado Rire et émancipation féminine: "Viragos, bruxas e prostitutas, de corpos transbordantes, são todas elas declinações da mulher desenfreada, herdeira das bacantes antigas" (Bayle/Fix 2013: 11). ${ }^{1}$ 
Catártico nestes últimos casos, o riso pode ser um acto de uma extrema subversão. As autoras de Novas Cartas Portuguesas, em todo o caso, insistem em que se trata de uma questão séria. Já na Terceira Carta II, lemos: “Quem me obriga a perder a seriedade do riso com que disse sim ao passeio convosco (...)?” (Barreno/Horta/Costa 2010: 26). E no final da mesma carta: "Está decretada a gravidade desta empresa. 0 que farei convosco será grave, ainda que para tanto haja que rir-me" (idem: 29).

Hélène Cixous opõe o riso feminino ao medo masculino:

Tanto faz que eles se arrasem ao descobrirem que as mulheres não são homens. Mas não será que este medo lhes convém? 0 pior não será que, na verdade, a mulher não é castrada. Basta olhar para a Medusa frontalmente para a vermos: e ela não é mortal. É bela. E ela ri. (Cixous 2010: 54)

Com efeito, em Novas Cartas Portuguesas, o riso impedido pelo medo tanto perturba Mariana como o poder inquisitorial: "Comuna de mulheres ou sufragistas já nos dizem, com riso gelado pela insegurança de nos verem juntas" (Barreno/Horta/Costa 2010: 100). Por outra parte, o riso do poder masculino pode ser uma violentação. D. Joana de Vasconcelos denuncia na sua carta (idem: 134) o riso do marido que "odeia tudo o que amo, ridicularizando sempre os meus sentimentos, destruindo-os pela sua delicadeza e sensibilidade com grande prazer e riso, brutalmente". Ao contrário, o riso feminino aparece como um processo, libertador e catártico, que se origina no mais íntimo do ser, na solidão do sujeito feminino que Irene Lisboa tão bem tematizou. 0 riso do sujeito feminino desconstrói a imagem imposta pela sociedade judaico-cristã, contrariando tanto a dor da ausência quanto a imposição do silêncio. Pela sua persistência, este riso insiste em perverter a compostura, afirmando uma postura outra, "o outro lado" (idem: 76). Trata-se de uma recuperação da perversão, traço moral instrumentalizado pelo poder patriarcal, no intuito da afirmação daquele "outro lado": "Era perversa: tinha um riso liberto, sedento, e uma maneira envolvente de olhar os outros; um odor enlouquecido a entreabrir-se aos poucos, como um fruto, obsessivo: obsessivamente, obsessivamente" (idem: 130). Vemos aqui o processo da libertação activado pelo uso repetido do gerúndio e pela imagem da maturação do fruto. Ana Luísa Amaral fala, na sua edição comentada das Novas Cartas 
Portuguesas, de "apropriação paródica" a propósito do epíteto "lésbicas" que o discurso falogocêntrico aplica às autoras. Ora, a paródia é uma forma da resistência e da persistência do riso feminino. Pela paródia impõe-se o ser verdadeiro de Fichte.

Em Novas Cartas Portuguesas, esta figura da ironia delineia o sujeito político colectivo do "Quem aguentá-lo pode". Neste sentido, a obra das Três Marias parece religar-se ao discurso de Althusser, para quem os argumentos biológicos, religiosos, psicológicos ou outros se valem, pois todos são os de uma ideologia dominante, quer dizer, pertencem a um aparelho discursivo que visa assegurar a dominação de uma classe por outra, dum grupo por outro (numa relação dialéctica com as classes): “(...) o problema não será só de capataz ou patrão, mas o de uma sociedade ser também construída a partir disto, do significado do trabalho e de quem o faz - se resistente é a economia e a política, mais é tudo o que as sustém" (idem: 81).

Neste contexto, o riso constitui uma das armas de resistência mais eficazes contra a ameaça, sempre presente, de redução do indivíduo a categorias alienantes preestabelecidas que exprimem o conjunto das opressões políticas, no seu sentido mais lato, e que pretendem privar os indivíduos, muito especialmente as mulheres, da sua própria integridade.

A determinação está bem clara. Como explica Ana Luísa Amaral no seu prefácio, a opressão levará as mulheres a fazerem "um Outubro, um Maio, e novo mês para cobrir o calendário" (idem: 3). Um mês de revolta e "vinganças" ("vinganças" ou "nostalgias"?). 0 objectivo do projecto está claramente estipulado: fazer uma "rosa de riso" (idem: 304), juntando todas as forças numa só comunidade/irmandade que levará à "morte da diferença, o chão da revolução", que será o "bom riso à flor da mão" (ibidem). 0 caminho ainda vai longo, porque as mentalidades não estão prontas: "há muita gente que ainda tem de aprender a rir - projecto da revolução - e à mão só há graças parvas (idem: 286).

No fim do processo, o riso que desconstrói levará à reconstrução através duma revolução das mentalidades:

Pela manhã deixo o Sol pousar-me nos braços, dou-lhe a nuca e aqueço-me da cor do chão azul dos 
lírios bravos, os pontos-riso das papoilas (...) até à linha poeirosa do horizonte mansamente em fogo, na minha boca de sorriso posto o Sol, isto é, os olhos dele ontem, a sua boca nova, a morna noite, a mão na quebra da cintura em sono, a confiança. (idem: 241)

Trata-se de uma revolução política no sentido lato, no sentido de civilidade ou Politikos, que aponta para o quadro geral de uma sociedade organizada e desenvolvida, em que a revolução consistiria na construção de uma relação diferente do outro, uma relação de igualdade, uma revolução que é explosão do riso, o outro podendo ser então o sujeito absoluto criador de novas escritas.

Por isso, à pergunta "Mas o que pode a literatura?" da Terceira carta V (idem: 197), respondem as autoras: "As palavras não substituem, mas ajudam. (...) cá ficamos à espera do poder criador e actuante da palavra" (idem: 288).

Este poder projecta uma nova poética do riso:

Que rimos ou rimamos nós de Mariana? Que negamos?

Que tiramos nós, Mariana? Seu cuidado?

É o meu cuidado?

Vocês, vosso cuidado?

Nossa chama?

Se dela tomei partido é porque a invento, não porque a disfarço. É porque a defendo? Me defendo? Me evito, amo, a suicido, a mato, a masturbo. (idem: 77)

Nesta citação, o sujeito político colectivo, pela transfiguração da criação, passa para um sujeito absoluto singularizado, que se efectivará em vários textos de autoria feminina posteriores a Novas Cartas Portuguesas.

O caso mais significativo, a nosso ver, é o riso de Maria Badala em a Casa de Cabeça de Cavalo, de Teolinda Gersão. Empregada da casa, Maria Badala transcende a sua condição pelo riso, desafiando o rigor imposto pelo chefe de família, Duarte Augusto. 0 seu nome é altamente simbólico pois com o seu riso badalado, abala as fundações morais da casa: "Ela ria. E o seu riso abanava a Casa, que tremia até aos alicerces..." (Gersão 1995: 179). Maria Badala espera que as meninas da casa sejam capazes de se libertar da ordem estabelecida: 
“(...) Se ao menos arrotassem. Assim, no meio da sala, aproveitando um silêncio, uma pausa na conversa. Zás. E já estava: Um arroto no ar, como um pano rasgado, um buraco aberto na cortina" (idem: 180). Por isso, ela ensina-lhes o riso: "Desde muito pequenas insistia: Põe a mão na anca. Deita para a frente a cabeça. Enche o peito de ar, a garganta, a boca, a barriga. Enche, enche. Agora solta, larga de uma vez. Como se estivesse um cão, uma cobra lá dentro. Vomita, deita fora, atira para longe. Assim" (idem: 179-180).

Mais um degrau, e passa-se da aprendizagem do riso libertador ao riso iniciático que permite à discípula da novela O Mestre (1963) de Ana Haterly constituir-se em sujeito absoluto, um riso iniciático que reencontramos numa obra mais recente com a NeoPenélope (2007), da mesma autora.

Por sua vez, ficcionando o modelo das Novas Cartas Portuguesas, Fernanda Botelho publica em 1998 Contadoras de Histórias. Uma gargalhada subversiva e libertadora pontua cada uma das histórias contadas pelas três mulheres, lembrando assim o processo generativo da obra das Três Marias:

- Gostei. Um tanto confuso, mas in-ten-so, como agora se diz. És uma apotegmática dos lugares-comuns.

- Esquizofrénica, ah!, ah!, ah! Mas, Ana querida, não te esqueças de que as moscas são indiscutivelmente tuas.

Desatam a rir.

- Que conversa surrealista!

- É do tempo que vivemos, e sai mais um lugar-comum para a mesa de três. (Botelho 1998: 61)

Ou pense-se na ligação entre o riso libertador e a obra de Agustina Bessa-Luís, que, apesar de menos evidente, se efectua através das personagens de Quina e de Sibila, assim como das feiticeiras da fonte em Eugénia e Silvina, culminando, mais recentemente, em $A$ Ronda da Noite: Rembrandt “[p]inta por vocação, por mania, por encomenda, por riso, por prazer" (Bessa-Luís 2006: 220). Isto acontece pela mediação surreal da musa que é a criança Saskia, que ilumina a cena representada pelo quadro. 0 papel da musa, para Agustina Bessa-Luís, consiste em conferir ao quadro o movimento que anima o pincel de 
Rembrandt entregue ao riso de prazer. Isso faz da criança Siskia "a pequena fada [que] saiu do quadro e se precipita para fora" (idem: 228). 0 narrador anuncia: "Quando ela chegar ao outro lado do quadro, talvez tudo já tivesse mudado" (ibidem). Assim, o riso ficcionalizado do pintor é traduzido pelo movimento "hors-cadre" de Saskia, feita personagem da ficção.

Da mesma maneira, Ana Marques Gastão, no seu livro Nós, partindo dos retratos de mulheres de Paula Rego, vê na dança a mesma leveza do movimento libertador do riso: "Eu, artífice da imaginação, deito-me na mansidão da página,/ olhos fechados, lábios fingindo agilidade, o verso espraiando-se/ na evocação de um amor antigo. Tu, mais esquecida da tua natureza,/ danças melhor, ave nítida, até ao limite de uma fantasia incontrolada" (Gastão 2004: 98). E a própria Maria Teresa Horta retoma o motivo da dança no fim do seu libreto da ópera As Feiticeiras (2006).

Voltando à carta da qual o nosso mote foi tirado, encontramos o desejo de leveza que o movimento da corrida e da dança impulsam nas autoras que acabamos de comentar. E as artes conjugam-se para libertar o riso sob todas as suas formas:

(...) o riso é a única coisa que deveras se faz nobremente e quem se mune de artes para dizer o que viu e ouviu, quem escreve e pinta ou marca de outro modo que o soez é porque o soez apouca e dele se ri - Nem na há outra receita de liberação de nada a não ser de vinde a mim os pequenos, que eu, porque não posso matar-me, de lhes ser diferente, lhes darei tamanho e tão amantíssimo pontapé no cu que nunca mais poderão assentar-se com descanso e lombe de outrem que pareça com eles a lombar-se. E estas coisas só as saberemos pelos baixos acima e nunca pela inversa.

E muitas e muitos serão chamados à liberdade e poucas e poucos serão escolhidos a esta maldição dela que é ter a palavra gostosa, o coração curioso e airado e o pé ligeiro (que às vezes lá se empala a melhor pata). (Barreno/Horta/Costa 2010: 272-273) 


\section{NOTA}

${ }^{1}$ No original: «Viragos, sorcières et prostituées au corps débordant sont autant de déclinaisons de la femme effrénée, héritière des bacchantes antiques». Excepto quando indicado, todas as traduções são da responsabilidade das autoras.

\section{Bibliografia}

Barreno, Maria Isabel/ Maria Teresa Horta/ Maria Velho da Costa (2010), Novas Cartas Portuguesas, Edição anotada, Org. Ana Luísa Amaral, Lisboa, Dom Quixote.

Bayle, Ariane /Florence Fix (2013), Rire et émancipation féminine, Paris, L’Harmattan.

Bessa-Luís, Agustina (2006), A Ronda da Noite, Lisboa, Guimarães Editores.

Botelho, Fernanda (1998), As Contadoras de Histórias, Lisboa, Editorial Presença.

Cixous, Hélène (2010), Le Rire de la Méduse et autres ironies, Préf. Frédéric Regard, Paris, Galilée.

Gastão, Ana Marques (2004), Nós, Lisboa, Gótica.

Gersão, Teolinda (1995), A Casa da Cabeça de Cavalo, Lisboa, Dom Quixote.

Horta, Maria Teresa (2006), Les Sorcières / Feiticeiras, Paris, Actes Sud-Musicatreize. 
Catherine Dumas é Professora Emérita da Universidade Sorbonne Nouvelle-Paris 3 e especialista em poesia contemporânea e romances de escritoras, tendo publicado neste domínio o livro Estética e Personagens nos romances de Agustina Bessa-Luís (Campo das Letras, 2002). Coordena as equipas de dois programas internacionais financiados pela Fundação para a Ciência e a Tecnologia. De um resultou um livro colectivo, Novas Cartas Portuguesas Entre Portugal e o Mundo (org. Ana Luísa Amaral e Marinela Freitas, 2014). 0 outro, ainda em curso, intitula-se "Poetics of selhood". Colabora regularmente com a revista portuguesa Colóquio/Letras, entre outras. É também tradutora de poesia, teatro e ficção portuguesa.

Agnès Levécot é Maître de Conférences na Universidade Sorbonne Nouvelle-Paris 3 e especialista do romance português pós-25 de Abril e africano de língua portuguesa. Publicou, em 2009, Le roman portugais contemporain. Profondeur du temps nas edições L'Harmattan. Participou de numerosos colóquios e colabora com várias revistas internacionais. Integra as equipas francesas de dois projetos internacionais da Fundação para a Ciência e a Tecnologia: do primeiro resultou um livro colectivo intitulado Novas Cartas Portuguesas, entre Portugal e o Mundo (org. Ana Luísa Amaral e Marinela Freitas, 2014) e o segundo, ainda em curso, intitula-se "Poetics of selhood". 